\title{
The Iris Effect: A Review
}

\author{
Richard S. Lindzen ${ }^{1} \cdot$ Yong-Sang $\mathrm{Choi}^{2}$ (I)
}

Received: 16 November 2020 / Revised: 11 January 2021 / Accepted: 19 March 2021 / Published online: 1 April 2021

(C) The Author(s) 2021

\begin{abstract}
This study reviews the research of the past 20-years on the role of anvil cirrus in the Earth's climate - research initiated by Lindzen et al. (Bull. Am. Meteor. Soc. 82:417-432, 2001). The original study suggested that the anvil cirrus would shrink with warming, which was estimated to induce longwave cooling for the Earth. This is referred to as the iris effect since the areal change hypothetically resembles the light control by the human eye's iris. If the effect is strong enough, it exerts a significant negative climate feedback which stabilizes tropical temperatures and limits climate sensitivity. Initial responses to Lindzen et al. (Bull. Am. Meteor. Soc. 82:417-432, 2001) denied the existence and effectiveness of the iris effect. Assessment of the debatable issues in these responses will be presented later in this review paper. At this point, the strong areal reduction of cirrus with warming appears very clearly in both climate models and satellite observations. Current studies found that the iris effect may not only come from the decreased cirrus outflow due to increased precipitation efficiency, but also from concentration of cumulus cores over warmer areas (the so-called aggregation effect). Yet, different opinions remain as to the radiative effect of cirrus clouds participating in the iris effect. For the iris effect to be most important, it must involve cirrus clouds that are not as opaque for visible radiation as they are for infrared radiation. However, current climate models often simulate cirrus clouds that are opaque in both visible and infrared radiation. This issue requires thorough examination as it seems to be opposed to conventional wisdom based on explicit observations. This paper was written in the hope of stimulating more effort to carefully evaluate these important issues.
\end{abstract}

Keywords Iris effect $\cdot$ Anvil cirrus $\cdot$ Cloud feedback $\cdot$ Infrared radiation

\section{Introduction}

Cirrus refers to the upper-level thin clouds that consist almost entirely of ice particles. As saturation vapor pressure of ice is low, particles of cirrus clouds evaporate slowly and are readily advected over long distances by strong upper-level winds (Houze Jr. 2014). For this reason, cirrus cover large areas of the Earth with daily variability on the order of millions of square meters. Very high-altitude cirrus whose base is above $10 \mathrm{~km}$ are concentrated within the western tropical Pacific (Mace et al. 2009). Of those cirrus, about half appear to

Responsible Editor: Hyemi Kim.

Yong-Sang Choi

ysc@ewha.ac.kr

1 Massachusetts Institute of Technology, Building 54, Room 1410, Cambridge, MA 01239, USA

2 Ewha Womans University, EngineerB 353, 52 Ewhayeodae-gil, Seodaemun-gu, Seoul 03760, South Korea originate from the upper parts of cumulonimbus (anvil cirrus) and the other half appear to form in situ due to the large-scale dynamics (Luo and Rossow 2004; Reverdy et al. 2012). Such anvil cirrus clouds play a key role in moistening the upperlevel air that otherwise would have been extremely dry (the water vapor above $5 \mathrm{~km}$ is only $10 \%$ of the total column water amount on the average). Consequently, the upper tropospheric anvil cirrus and moist area in the vicinity of clouds may reduce outgoing longwave (or infrared) radiation escaping from the Earth. The anvil cirrus, especially the optically thick part near the cumulonimbus, also blocks incoming shortwave (or visible) radiation (Kiehl 1994). Such anvil cirrus play an important role in the Earth's radiative budget.

As tropical deep convective activities are highly affected by surface temperature, anvil cirrus from the deep convective system would also be responsive to surface temperature (a cloud feedback). This is being found quite clearly with active satellite observations such as CloudSat (Igel et al. 2014), but it came as a surprise when it was first suggested by a paper titled "Does the Earth have an adaptive infrared iris?" by Lindzen et al. (2001) (hereafter LCH01). LCH01 hypothesized that the 
region of anvil cirrus could control the tropical outgoing energy by reducing their areal coverage with warming. By the hypothesis, the counteractive effect on the incoming energy was considered as well, but it turned out to be secondary. It is this behavior that was referred to as the iris effect. LCH01 observationally tested the iris effect with geostationary infrared imagery over the tropical western Pacific. Although several assumptions are required for the estimation of the impact on climate sensitivity, $\mathrm{LCH} 01$ argued that the iris effect would be of fundamental importance in climate projection - a consequence of the combination of several radiative feedbacks associated with cloud, water vapor, etc. This paper reviews the research in the 20-years since LCH01.

LCH01 showed that it was no longer possible to disentangle the radiative impact of changes in water vapor from that due to changes in upper-level cloud cover, especially since the upper-level cirrus, when present, rather than the water vapor, determine the infrared emission level. Instead, it is necessary when dealing with feedbacks, to consider a longwave feedback that incorporates the combination of cloud, water vapor and areal responses to temperature. This has led subsequent studies to examine the change in the top-of-the-atmosphere longwave radiation instead of cloud and water vapor individually. As we will show later, many studies found negative longwave feedback consistent with the iris effect (Lindzen and Choi 2009, 2011; Choi et al. 2014; Mauritsen and Stevens 2015). Nevertheless, it is a subject of controversy to what extent the shortwave feedback compensates for the longwave feedback; some studies also assert that the compensation would give nearly zero net radiative feedback in the iris effect (Sherwood et al. 2020).

Recently, papers have investigated sources other than what was considered by LCH01 for the origin of the iris effect. The original idea of $\mathrm{LCH} 01$ was that the iris effect is associated with decreased cirrus outflow due to the increased precipitation efficiency with warming. However, subsequent studies showed the iris effect may also be the manifestation of additional atmospheric processes. Wing and Emanuel (2014) and Muller and Bony (2015) suggested that something like the iris effect (i.e., the shrinkage or tardy response of anvil cirrus area with warming) clearly appears in the increased convective aggregation with the increased temperature. Similarly, the iris effect was observed as the manifestation of the concentration of cumulonimbus over warmer regions (Choi et al. 2017; Saint-Lu et al. 2020), and the strengthening of Hadley circulation ( $\mathrm{Su}$ et al. 2017). Bony et al. (2016) argued that the convective anvil shrinkage is rooted in basic energetics and thermodynamic properties of the atmosphere. They said the clouds find themselves in a more stable atmosphere which reduces the convective outflow in the upper troposphere. These mechanisms, while different from LCH01 in terms of the origin, reconfirm the existence of the iris effect. The present review will consider all these studies that seemingly imply the iris effect.
In order to understand the iris effect, it may be useful to review how the identification of the iris effect came to be. To this end, we begin with the historical background in Section 2 . Section 3 will deal with the comments claiming to have refuted the results of LCH01. Section 4 will discuss where things appear to stand at the moment. Section 5 points out that the current climate feedback study is confronted with signal-tonoise problems. Section 6 will briefly describe some areas in particular need of more work. Some of these things have been dealt with earlier (Lindzen 2012). As to the original idea of the iris effect, the matter is treated in greater detail in the original paper (LCH01).

\section{Historical Background of the Iris Effect}

Most people working on climate initially, assumed that relative humidity remained fixed as climate changed, and that, therefore, following Manabe and Wetherald (1975), there was a water vapor feedback (Lindzen et al. 1982). However, Lindzen (1990), in response to a review, had suggested the possibility of a mechanism for reducing the water vapor feedback. Subsequent calculations showed the proposed mechanism would be ineffective. A careful study of the water vapor budget was begun leading to the following paper (Sun and Lindzen 1993). Microwave observations of water vapor by Spencer and Braswell (1997) made it clear that there was an additional factor that was going to be crucial: namely the fact that above the boundary layer, there was a clear delineation between moist and dry regions - a result, possibly, of an instability in radiative-convective equilibrium (Nilsson and Emanuel 1999), and that the behavior of any water vapor feedback would have to take account of the relative areas of these regions. These findings motivated LCH01.

The original emphasis in LCH01 was, indeed, on the behavior of the water vapor, but an important practical consideration forced LCH01 to focus on cloud cover. Namely, in order to observe the detailed response of cloudy area to surface temperature, LCH01 had to use geostationary data; the available satellite (Japanese GMS5) measured brightness temperature which could be used to estimate cloud cover, but could not measure water vapor. It was also unable to detect thin cirrus. However, LCH01 used measurements of thicker cirrus as surrogates for total cirrus. Their first instinct was to use the relation found by Udelhofen and Hartmann (1995) to assume a nearly linear positive relation between high cloud and humidity. However, in the course of the calculations, LCH01 realized that the clouds themselves were a major factor in the longwave budget, and allowed for water vapor and clouds to be unrelated. This, of course, minimized negative feedbacks (i.e., feedbacks that diminished rather than amplified the response to radiative forcing; conversely, positive feedbacks amplify the response.), which might otherwise be overestimated by a coherent relation 
of humidity and clouds. Nevertheless, the feedbacks were negative because it was found that high thin cirrus cloud cover, when normalized by a measure of cumulonimbus mass flux, diminished with increases in temperature allowing enhanced cooling. Tropical cirrus originate from convective cores. The normalization was crucial to obtain cirrus cloudiness per a unit convective core; without normalization, the results would simply reflect the concentration of cumulus activity over warm regions (Choi et al. 2017).

Much of the rest of LCH01 was devoted to the description and implementation of simple calculations to infer the impact of the iris effect on the climate sensitivity. The limitations of LCH01 were carefully described. Although the iris effect was naturally restricted to the tropics where cumulonimbus convection is a dominant process, the radiative impact of the iris effect was averaged over the globe in order to estimate the impact on climate sensitivity. Again, the details are given in LCH01. The results suggested a very strong negative feedback that would cancel the positive feedbacks in current climate models. LCH01 also showed that the few climate models, then available, differed sufficiently from the observations to overwhelm the uncertainties in the observations. The final suggestion of LCH01 was that modelers should incorporate the iris effect into climate models to see how it would impact results. It took about 14 years for Mauritsen and Stevens (2015) to take up this modest suggestion. In the interim, LCH01 was subjected to harsh criticisms - especially between 2002 and 2005. These will be described in the next section.

\section{Subsequent Criticisms and Rebuttals}

The first response to LCH01 came as a separate article by Hartmann and Michelsen (2002a). The title of the article was "No Evidence for Iris" and the new editor of the Bulletin of the American Meteorological Society appended a subtitle "Careful analysis of data reveals no shrinkage of tropical cloud anvil area with increasing sea surface temperature (SST).". The basic assertion of Hartmann and Michelsen (2002a) was that the stratiform clouds LCH01 was looking at did not originate in cumulonimbus convection. Rather, the paper claimed that clouds are associated with extratropical systems that intrude into the tropics. In LCH01, however, SST was weighted by cloud cover since clouds would not respond to SST over the whole domain, but SST beneath the cloud. As shown by Lindzen and Christy (2020), global mean temperatures bear little relation to local temperatures.

In fact, the assertion of Hartmann and Michelsen (2002a) was grounded by correlation analyses between cloud amount for 'each grid' and cloud weighted SST averaged 'over the whole domain'. The pitfall of this grid-based analysis will be shown in contrast with the area-averaging analysis in the next section. What the paper showed was a strong negative correlation between cloudiness and SST over some subtropical regions, but no such relation near the equator, was associated with strong equatorward winds from the exterior of the tropical western Pacific (TWP; $120^{\circ} \mathrm{E}-155^{\circ} \mathrm{W}, 30^{\circ} \mathrm{S}-30^{\circ} \mathrm{N}$ ) studied in LCH01.

Lindzen et al. (2002) pointed out that the analysis by Hartmann and Michelsen (2002a) is not appropriate to test the iris effect since the way they analyzed the data cannot capture clouds popping up in different locations over the TWP and moving to the next grid. Hartmann and Michelsen (2002b), in their reply to Lindzen et al. (2002), agreed that "the specific meteorological origin of the cloud anomalies is less relevant" and admitted their result is consistent with Lindzen et al. (2002), suggesting "the deep convective core clouds do exist outside the near equatorial region and over colder SST". However, Hartmann and Michelsen (2002b) reasserted that the data do not support the iris effect due to too high sensitivity of the statistics to cloud weighted SST.

In any event, the Hartmann-Michelsen assertion was that a tropical-subtropical contrast distorts climate sensitivity. Their paper would remain doubtful for at least two reasons: (i) The iris effect would diminish as we restricted ourselves to regions closer to the equator if Hartmann and Michelsen (2002a, 2002b) were correct. If anything, the effect increased. (ii) Close examination of GMS5 data permitted one to identify cumulonimbus cores associated with cirrus in all parts of the domain.

Del Genio and Kovari (2002) noted that when they looked at a warmer region and a cooler region in the tropics, they found more upper-level cloud cover in the warmer region in contrast to what the iris effect would suggest. However, this simply reflected the general phenomenon that "convection preferentially occurs over the warmest surface temperatures" (Mauritsen and Stevens 2015). Thus, it may easily appear as if upper-level cloud cover increases with temperature. Unfortunately, they failed to distinguish cloud cover from cloud cover per unit cumulus tower (area with $11-\mu \mathrm{m}$ brightness temperature less than $220 \mathrm{~K}$ in LCH01). The iris effect refers to the latter. As Rondanelli and Lindzen (2008) noted later, when the normalization was applied, they actually found a stronger iris effect than LCH01 had estimated. As we will explain later, the movement of convection to the warmest surface will eventually reduce the actual area of anvil cirrus for the given TWP domain.

Two other critical papers (Fu et al. (2002), and Lin et al. (2002)) argued against the LCH01's treatment of the radiative effects of the upper level cirrus. As noted in the responses (Chou et al. 2002a, 2002b), both these criticisms argued that $\mathrm{LCH} 01$ had misrepresented the radiative properties of upper level cirrus by overemphasizing their infrared effect and understating their visible effect. Lin et al. (2002) concluded that the main impact of upper level clouds was in the visible. 
The disparate findings may arise from small differences in albedo over tropical moist and dry regions: 0.27 and 0.21 for LCH01 versus 0.31 and 0.15 for Lin et al. (2002), and more importantly, from different fractional coverages of the tropical high cloud within a moist region: 0.44 for LCH01 versus 0.2 for Lin et al. (2002). Note that dry regions do not only include clear-sky albedo (0.13), but also low-level cumulus or stratocumulus that have a high albedo (0.42). LCH01 were taking $\mathrm{Ac}(260)$ (i.e., area of $11-\mu \mathrm{m}$ brightness temperature $<260 \mathrm{~K}^{1}$ ) as a surrogate for all tropical upper level cirrus. Later, Choi et al. (2005) show that $A c(260)$ takes just about half of the MODIS high-cloud amount determined by $1.38-\mathrm{mm}$ reflectances $(>1.1 \%)$ since the minimum detectable value of optical depths by the GMS5 and MODIS measurements is around 2.0 and 0.1 , respectively. Therefore, much of very thin cirrus clouds were missing in $\mathrm{Ac}(260)$ and the high cloud fraction of 0.44 for LCH01 may not be too large (Mace et al. 2009). For the very thin cirrus, thicker cirrus with and without underlying low clouds (which total-column optical depth $<\sim 9$ ), the infrared effect was found to dominate over the visible effect in satellite observations from CERES and MODIS (Choi and Ho 2006). Likewise, virtually all papers dealing with the impact of clouds on climate agree that for upper level cirrus, the primary radiative impact is in the infrared (e.g., Liou 1986). Thus, LCH01 focused on the clouds in the immediate vicinity of the cumulus cores which are atypically thick and do have a high albedo. LCH01 have already noted that separating thick clouds from thinner clouds did not change the magnitude of the effect. Neither did changing the reference brightness temperature. In brief, these criticisms managed to change the results obtained by LCH01 by claiming that LCH01 had followed an inappropriate procedure different from the one actually employed.

Perhaps the most misleading criticism was that due to Lin et al. (2004). As noted by Chou and Lindzen (2005), Lin et al. (2004) assumed differences from LCH01 imply the absence of negative feedbacks, but the negative feedbacks implied by their results are larger than those in LCH01. Similarly, they assumed that the discrepancies between their specification of cloud radiative properties and the observations is due to their use of the iris result that cloud cover diminishes $22 \%$ per degree. What they failed to note was that to bring their values into line with observations, they would need much more than $22 \%$.

Several studies simply could not find direct evidence supporting the iris effect with currently available satellite data: direct energy observing CERES data (Chambers et al. 2002), and TRMM data (Lin et al. 2006; Rapp et al. 2005). TRMM data were expected to offer precipitation efficiency in the deep

\footnotetext{
${ }^{1}$ This value is much higher than the actual cloud top temperature since it corresponds to the total radiances emitted from both the cloud top and the surface layer.
}

convective cloud system, so as to allow exploration of the mechanism behind the iris effect. However, as $\mathrm{Su}$ et al. (2008) noted, cloud information derived from TRMM data may not capture the upper tropospheric thin cirrus clouds. Their suggestion was that the iris effect should also take into account radiative effects of upper tropospheric cloud water content variation related to cloud optical thickness, in addition to cirrus fraction. Likewise, Kubar and Jiang (2019) used the 2-year MISR data combined with the other satellite data to show overall thinning and top-heaviness of clouds with increasing SST over TWP, but failed to find the iris effect. As shown in Igel et al. (2014) and Choi et al. (2017), however, recent satellite observations very likely do contain the iris effect.

Though several rebuttal points were briefly reviewed here, for further information, readers may look over Lindzen et al. (2002) comments on Hartmann and Michelsen (2002a), Chou et al. (2002a) on Fu et al. (2002), Chou et al. (2002b) on Lin et al. (2002), Chou and Lindzen (2005) on Lin et al. (2004), and Rondanelli and Lindzen (2010a) on Su et al. (2008). The results of these comment papers are not again refuted in the literature since then. In the next section, subsequent papers viewed somewhat different, but relevant points, leading to the gradual evolution of the argument for the iris effect beyond the original argument by LCHO1.

\section{Advancing the Iris Effect Study}

Rondanelli and Lindzen (2008; 2010a) used the ground-based radar at Kwajalein as well as Tropical Rainfall Measuring Mission (TRMM) satellite data to examine aspects of the iris effect. In particular, the iris effect implied that precipitation efficiency in cumulonimbus towers would increase with increasing SST, and that the area of stratiform detrainment from these towers would decrease. The Kwajalein ground radar offered good resolution and coverage. As usual, one needed to be careful about adequate time intervals. At the least, one had to avoid sampling only one part of the time evolution of the cloud system. However, they found that at any given time the radar was sensing a large number of systems at different stages of evolution, and this minimized the issue. Rondanelli and Lindzen (2008) found that convective precipitation increased $\sim 10 \% / \mathrm{K}$ while stratiform area decreased $\sim 22 \% / \mathrm{K}$ - consistent with the earlier results from LCH01. TRMM data provided coverage over the whole tropics, but with poor time resolution and other problems: perhaps most notably an inability to detect low levels of precipitation. Still, the TRMM data also showed increases of convective precipitation $(\sim 7 \% / \mathrm{K})$ and decreases of stratiform area $(\sim 5 \% / \mathrm{K})$ albeit at a reduced level (though TRMM showed great regional variability with some regions showing much larger values). Thus, a variety of independent approaches (Del Genio and Kovari 2002; Horváth and Soden 
2008; LCH01; Rondanelli and Lindzen 2008; Rondanelli and Lindzen 2010a; Igel et al. 2014; Igel and van den Heever 2015; Choi et al. 2017; Saint-Lu et al. 2020) have all confirmed the iris effect, though there is uncertainty as to the exact magnitude of the effect (Sherwood et al. 2020). As already noted, Del Genio and Kovari (2002) required normalization to show the effect. The reason for increased precipitation efficiency with increasing SST is, of course, not resolved by these studies.

The issue of normalization warrants some discussion. The normalization used by Rondanelli and Lindzen (2008) was total precipitation. LCH01 recommended cumulus mass flux. Whatever the choice is, as noted by Rondanelli and Lindzen (2008), "the normalization is a necessary condition to obtain a meaningful result since to the first order the SST distribution organizes the spatial variation of convection in the tropics. Cloud properties such as the area of detrainment, total rainfall, and cloud radiative effects can be considered extensive with respect to the amount of convection. The normalization simply takes into account the fact that the amount of convection in a region of a given temperature is not indicative of the amount of convection in a climate with the same temperature, since the global amount of convection is determined by global energy balance considerations. It remains an open question whether total precipitation, mass convective flux, or some other measure of convection is the most appropriate normalization factor with regard to climate effects." LCH01 noted that if relative humidity in the tropical boundary layer remained constant as climate changed, the cumulus mass flux was the appropriate normalization. However, small changes in relative humidity would lead to different choices, and until we have a good basis for predicting such changes, the exact choice of normalization remains uncertain. There is no guarantee that the normalized results will provide a reliable quantitative climate effect ( $\mathrm{Su}$ et al. 2008) without relating it to radiative effects, but not normalizing the cloud variations by a measure of convection will surely provide a wrong answer (Rondanelli and Lindzen 2010a).

As an application of the iris effect, Rondanelli and Lindzen (2010b) considered its possible role in resolving the Early Faint Sun Paradox (Sagan and Mullen 1972). Briefly, Sagan and Mullen (1972) noted that according to the standard model of the sun, solar output should have been $20-30 \%$ less than today's between 2 and 3.5 billion years ago (remember that a doubling of $\mathrm{CO}_{2}$ represents only a $2 \%$ change in radiative balance.). This should have led to an ice-covered planet, but the geological evidence indicated flowing water and possibly the complete absence of ice. The most commonly proposed solutions involved large quantities of greenhouse gases, but each of these had profound difficulties. For example, the amount of $\mathrm{CO}_{2}$ required was at least ten times greater than permitted by geological evidence from paleosols and other proxies. Rondanelli and Lindzen (2010b) examined the potential of upper level cirrus in the tropics to resolve the problem and found that this was a possible solution. Invoking the iris effect with a magnitude of $-22 \% / \mathrm{K}$ allowed resolution without any additional greenhouse gas, while $-5 \% / \mathrm{K}$ allowed for an ice-free tropics while also allowing complete resolution with the addition of $\mathrm{CO}_{2}$ well within what was allowed by geological data.

The assertion by Hartmann and Michelson (2002a) "the upper-level cirrus fraction in LCH10 intruded into the TWP from the subtropics have led a negative correlation with SST." was tested with the 15-years of accumulated satellite data by Choi et al. (2017). They found that the assertion was groundless. The variation in upper-level cirrus arise from the equatorial convective cloud systems in the sub-area of TWP. As to the cloud radiative forcing, the direct response appears in SST tendency (the difference between the two consecutive months) rather than SST itself. Choi et al. (2017) showed that the cloud influence in SST tendency is trivial over the TWP, but significant over the tropical eastern Pacific. This means that the upper level cirrus over the TWP was influenced by SST, but not vice versa.

As already mentioned in Section 1, one important implication of the highly variable tropical upper-level cirrus (regardless of the iris effect), is that it is no longer possible to isolate the water vapor feedback from the infrared cloud feedback associated with upper-level cirrus. It is, rather, more appropriate to simply look for the infrared (longwave) feedback. Similarly, it is reasonable to look for a shortwave feedback as well. Lindzen and Choi $(2009,2011)$ using satellite data from the ERBE (Earth Radiation Budget Experiment) and from both ERBE and CERES (Clouds and the Earth's Radiant Energy System) respectively, investigated the dependence of variations in both longwave and shortwave radiation as seen from space on SST. We note that criticisms (Chung et al. 2010; Murphy 2010; Trenberth et al. 2010; Trenberth et al. 2011) came out against Lindzen and Choi (2009). They pointed out our misinterpretation of the observed tropical radiative dependence on SST with respect to 'global climate sensitivity'. In response to this criticism, Lindzen and Choi (2011) corrected the issue and again concluded that the sensitivity was low. Subsequently, Bates (2016) examined this in greater detail, attempting to improve the simple procedure of simply averaging feedbacks concentrated in the tropics over all latitudes.

As is common in feedback studies in other fields, it was necessary to restrict oneself to fluctuations over time intervals long compared to the time scale for the feedback processes while short compared to the time for climate equilibration (Lindzen and Choi 2009). Simply regressing over the whole time record (as in Forster and Gregory 2006) can and often does lead to biases in feedback estimation (explicitly shown in Figs. 6 and 7 of Lindzen and Choi 2011). What we found was a fairly clear negative longwave feedback, an ambiguous signal for the shortwave feedback, and large differences between model responses to specified SSTs compared to what was observed. 
The negative longwave feedback is compatible with the results of LCH01. Mauritsen and Stevens (2015) in introducing the iris effect into their model (by making precipitation efficiency increase due to clustering of convection in mesoscale systems) also found that the longwave feedback was essentially eliminated, but found that, in their model, shortwave feedback still provided a net positive feedback that brought climate sensitivity to the low end of the range in Intergovernmental Panel on Climate Change (IPCC) reports. The enhanced clustering of convection (and high cloud fraction decrease consistent with the iris effect) modeled in Mauritsen and Stevens (2015) has been found in several recent observational investigations (Zelinka and Hartmann 2011; Tobin et al. 2012; Choi et al. 2017; Saint-Lu et al. 2020).

A recent study by Choi et al. (2017) found the clusteringinduced observed negative relations between MODIS cirrus clouds and TRMM convective precipitations normalized by total precipitations (that is mainly due to clustering of convective towers) would give important constraints on equilibrium climate sensitivity (to $2 \times \mathrm{CO}_{2}$ ) lower than $3 \mathrm{~K}$ in current climate models (CMIP5) while leaving uncertain the actual value. Thus, it should be important to extract cloud feedback effects as reliably as possible for climate sensitivity. Current climate models simulate the climate sensitivity between 1.5 and $4.5 \mathrm{~K}$, and much of the uncertainty arises from cloud feedback (Sherwood et al. 2020). Note that some studies (including some from major data centers) also confirm the implausibility of higher climate sensitivities (Fyfe et al. 2013; Stott et al. 2013; Lewis and Curry, 2015; Lindzen, 2019).

\section{Signal-to-Noise Problems}

Studying feedback effects on clouds inevitably involves at least two intrinsic difficulties: measurements are always to some extent indirect (that is to say one does not in general measure cumulus mass flux or stratiform cloud area directly), and, perhaps more importantly, clouds depend on many factors other than surface temperature so that attempts to relate cloud cover to temperature have large scatters and relatively low correlations. As Rondanelli and Lindzen (2008) noted: "small values of the regression coefficients as the ones we observe do not imply a small effect but rather the presence of noise." This indicates that sufficient noise can render signal detection difficult, and, in some cases impossible (Choi et al. 2014).

This issue can be simply tested by relating the top-of-the atmosphere radiative flux anomalies $(R)$ to the sea surface temperature anomalies $(T)$. It is straightforward to take the regression coefficients of $R$ onto $T$ (hereafter, $R / T$ ) for confirmation of the $R-T$ feedback relation. We calculated the lagged $R / T$ based on monthly $R$ from CERES and $T$ from
NOAA OI SST in $1^{\circ} \times 1^{\circ}$ resolution for 20 years (March 2000 to February 2020). Figure 1 basically implies that observational $R / T$ s are very variable with the methods used for calculation of $R / T$. Figure 1a regressed $R$ onto $T$ area-averaged over the tropics $\left(20^{\circ} \mathrm{S}-20^{\circ} \mathrm{N}\right)([R] /[T])$, while Fig. 1b regressed $R$ onto $T$ from each $i$ th grid point within the tropics $\left(R_{\mathrm{i}} / T_{\mathrm{i}}\right)$.

The feedback relation between $R$ and $T$ is manifested at a simultaneous time, not a lagged time. Thus, the magnitude of the regression coefficient $R / T$ should be maximized at zero lag, but weaken with lag. This has been explicitly shown in Choi et al. (2014), and in their simulations, only the peaked $R /$ $T$ at zero lag securely represented a reliable feedback parameter. We do see a clear zero-lag peak of $[R] /[T]$ is $-4 \mathrm{~W} \mathrm{~m}^{-2} \mathrm{~K}^{-1}$ in the longwave (the red line in Fig. 1a) - a negative longwave feedback consistent with many previous studies (Lindzen and Choi 2011; Choi et al. 2014; Mauritsen and Stevens 2015).

Choi et al. (2014) also noted that the unclear regression coefficient $R / T$ is also induced by numerous non-feedback noise. For example, processes other than SST caused changes in clouds. That is, autonomous cloud-induced $R$ influences $T$ (but not vice versa). Also, the third factors (diurnal or seasonal solar illumination, ENSO, etc.) readily change both $R$ and $T$ regardless of $R-T$ feedback relation. These cases altogether make the $R / T$ peak at lagged time (e.g., ENSO effect shown in Trenberth et al. 2011), and the zero-lag $R / T$ far from a false feedback parameter. We reconfirm that it is hardly avoided by the simple regression in the shortwave (the blue line in Fig. 1a). Choi et al. (2014) noted that the noise dominated the attempted measurements of shortwave feedback leaving the feedback essentially undetectable.

In the grid-to-grid regression analysis (Fig. 1b), the sign of $R_{\mathrm{i}} / T_{\mathrm{i}}$ was even the opposite to $[R] /[T]$ in Fig. 1a. Moreover, very sharp $R_{\mathrm{i}} / T_{\mathrm{i}}$ peaks appear at 1 -month lag, and do not represent the feedback effect. This may be just due to the movement of convective clouds to the next grid $(i+1)$ where the surface has been warmer. $R_{\mathrm{i}+1}$ due to the clouds should have been related to $T_{\mathrm{i}}$ where the clouds popped up. Otherwise, the grid-to-grid relation readily misinterprets the feedback parameter.

For better assessment of the iris effect, some studies pointed out methodological advances are needed. Noting that part of the problem was that cloud changes could produce rapid changes in skin temperature of the ocean (which is what AVHRR is essentially measuring), Cho et al. (2012) found that using SST weighted according to the absence of clouds could reduce noise but not sufficiently to allow a reliable determination of the shortwave feedback.

Nevertheless, because this has led to more efficient terrestrial emission but less solar reflection (Trenberth and Fasullo 2009), its net radiative feedback effects continue to be questioned. Sherwood et al. (2020), in their review, inferred 

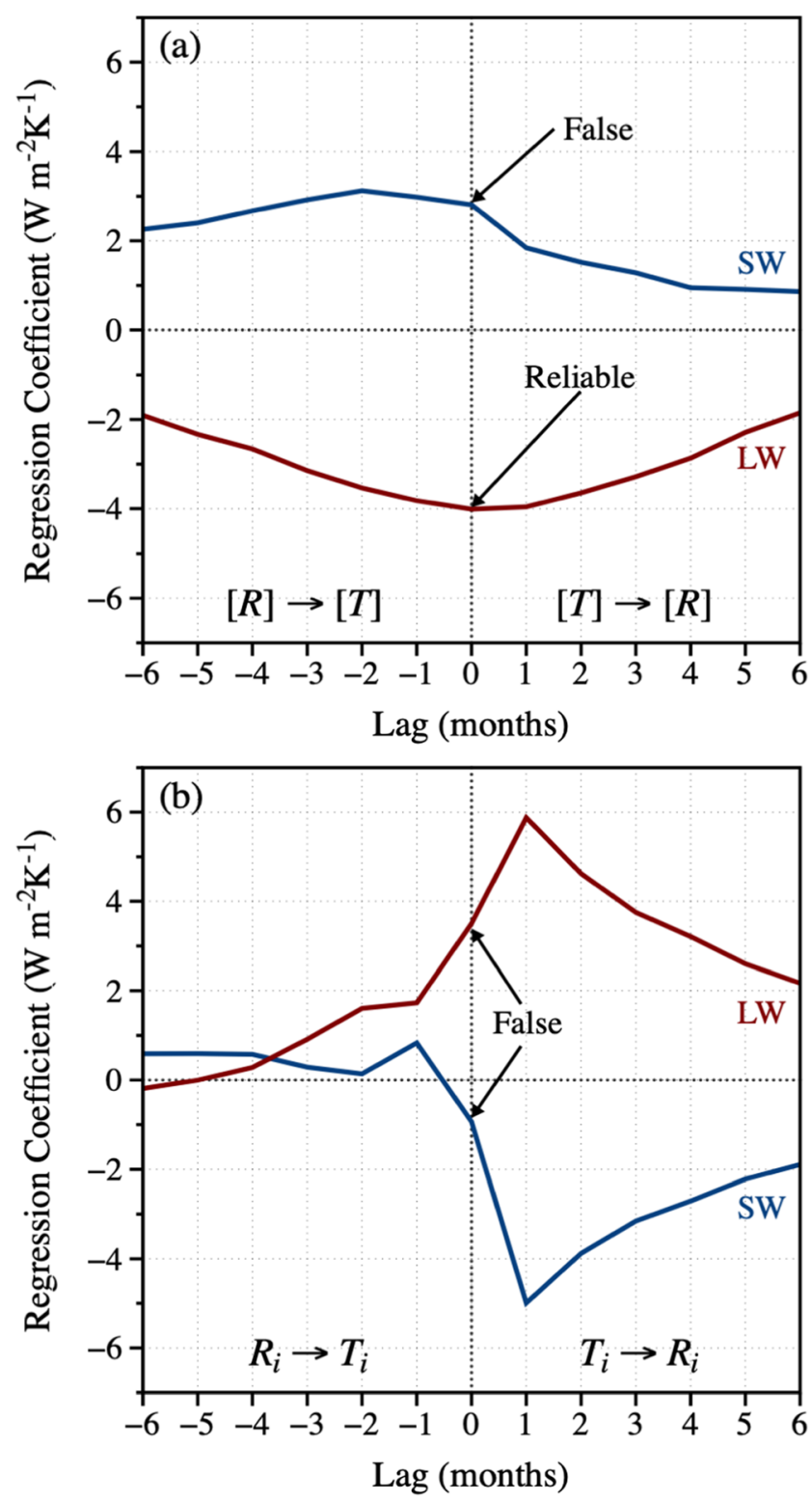

Fig. 1 The regression coefficients of the top-of-the atmosphere radiative flux anomalies $(R)$ onto the sea surface temperature anomalies $(T)$, based on the area-averages ([]) over the tropics $\left(20^{\circ} \mathrm{S}-20^{\circ} \mathrm{N}\right)(\mathbf{a})$, and $i$ th grid point values within the tropics (b). The negative (positive) lag means that $R$ precedes $T(T$ precedes $R$ ). The red and blue line indicates the longwave (LW) and shortwave (SW), respectively. Only the zero-lag regression coefficient of $-4 \mathrm{~W} \mathrm{~m}^{-2} \mathrm{~K}^{-1}$ in the longwave represents a reliable negative longwave feedback parameter consistent with many previous studies (Lindzen and Choi 2011; Choi et al. 2014; Mauritsen and Stevens 2015). The other regression coefficients are false feedback parameters. See the text for more details

that the net effect may be too small to substantially affect climate sensitivity (about $-0.2 \mathrm{~W} / \mathrm{m}^{2} / \mathrm{K}$ with a standard deviation $\left.0.2 \mathrm{~W} / \mathrm{m}^{2} / \mathrm{K}\right)$. We note that this value is based on Williams and Pierrehumbert (2017) which is a grid-to-grid analysis. They have also reviewed the possibility for the net effect to be positive (Lin et al. 2002; Chambers et al. 2002), and neutral (Zelinka and Hartmann 2011). The continual disagreements should be understood in line with Fig. 1. Studies without confirming the lagged relation between radiative fluxes and SST should be treated with extreme caution.

\section{Suggestions for Further Study}

As seen in subsequent studies, the iris effect remains a viable mechanism. To be sure, there remain such questions as the exact mechanism for precipitation efficiency (Sui et al. 2020), and the proper normalization for application to climate change. However, neither of these appears to be capable of changing the major conclusions.

Normalization (by either cumulus flux, total precipitation, or some combination) is still needed so as to look at the reaction of anvil cirrus per unit cumulus flux to SST warming. Otherwise, the iris effect would be underestimated (or veiled) because cirrus fraction is readily observed to increase with more cumulus towers concentrated on warmer areas. If possible, we recommend the normalization by total rain since that by the area of cumulus tower may be unresolved by grid-scale climate data.

Nevertheless, without the normalization, one can qualitatively find the reduction of cirrus with SST warming in various (both passive and active) satellite observations (Igel et al. 2014). Based on Choi et al. (2017), the best domain for the iris effect study would be the TWP that is used in LCH01. An area smaller than this domain could not stably capture the iris effect (Choi et al. 2017). The sub-areas of previous studies (Horváth and Soden 2008; Rondanelli and Lindzen 2008) would require normalization for discerning the iris effect. Therefore, the choice of domains is important, and comparison of smaller or larger tropical regions should be useful. Too small a domain may cut off total cirrus response, while too large domain invites subtropical influence. Dynamical coupling may be involved with the mechanism since several convective cloud systems embody the iris effect often by their dynamic aggregations (Wing and Emanuel 2014; Muller and Bony 2015).

It is advisable to use instrument platforms better suited to the measurements we have described. Microwave sensors on a geostationary satellite would be a significant help, but this does not seem likely for the immediate future. Hourly variation of upper-level clouds and moist areas in a geostationary satellite in relation to SST should be studied more carefully. According to LCH01 and the rebuttal papers, this geostationary imagery is important for studying the iris effect and may be a key to revealing something that cannot be seen from a sun-synchronous satellite in most previous papers.

Considerable uncertainty in the iris effect arises simply from SST per se. SST should be carefully selected especially when quantifying the iris effect. As LCH01 noted, cloudweighted SSTs beneath cumulonimbus towers are theoretically ideal, but those SSTs in sampling are heavily affected by 
the clouds themselves. SSTs often drop due to cloud shielding effects. Using this SST may obscure the clear delineation of anvil response to SST. To obtain SST as a pre-condition of convective cloud system, at least hourly cloud data are needed to screen out bad pixels. A more detailed discussion of possible methodology may be found in Cho et al. (2012).

Further observational evidence, clarifying the mechanism, should help models to incorporate the iris effect. It is also important to identify the differences between current climate modeling of cirrus clouds and the observations. Most of modeled cirrus cloud may not be those 'detrained' from cumulonimbus towers, but entirely long-lived condensates in situ at the upper levels (Seeley et al. 2019). This means that the iris mechanism is not in the model lacking cloud resolving schemes from the very beginning (Retsch et al. 2019). Modelers would have to select cloud fractions on the top one to three vertical levels (Choi et al. 2017; Li et al. 2019); the more cloud levels selected, the larger the cloud fraction and albedo calculated. In addition, the response of upper-level clouds to SST is dependent on the vertical resolution of the model (Ohno et al. 2019). Practically, the cirrus calculated have higher albedo than observed (Li et al. 2019). This difference certainly amplifies modeled shortwave radiative impact for any iris effect experiments. However, by appropriately implementing the iris effect, it is also true that climate models (including radiative-convective equilibrium models) may be useful to estimate the impact of the iris effect on global climate (Zhao et al. 2016). Recent studies use radiative-convective equilibrium models with the multiple cloud layers for assessment of the iris effect (Bony et al. 2016; Ohno and Satoh 2018). The issue of estimating the impact of tropical cloud feedbacks on the globe as a whole, should probably be reassessed in the light of recent work on baroclinic equilibration (baroclinic instability being the major source of meridional heat transport in the atmosphere (Jansen and Ferrari 2013; Lindzen 2020). In this connection, recent studies have shown that poleward energy transport in the atmosphere tends to prevent excessive Arctic warming (Hwang et al. 2019, 2020).

Again, the iris effect is basically an infrared feedback due to the large radiative effect of high cirrus in the infrared. Adding the shortwave effect to this process amplifies uncertainty considerably. In the combinations of MODIS and CERES satellite observations, the outgoing longwave radiation clearly decreased with the increase in cirrus fraction (Choi et al. 2017). In this calculation, the dependence of absorbed solar radiation on cirrus fraction was much weaker. Observational calculation of shortwave cloud radiative effects is commonly by clear-sky minus total-sky absorbed solar radiation (Williams and Pierrehumbert 2017). However, that approach gives rise to overestimation of the radiative effects of cirrus, since the calculated cloud radiative effect is not just of high cirrus clouds, but of all total-column clouds including much of low-level clouds below cirrus (Choi and Ho 2006).
Radiative transfer simulations show that variable low clouds below the cirrus clouds induce large variation in cloud radiative effects, even for a given fixed top pressure of high clouds and the fixed total column cloud optical thickness (Kang et al. 2020). The iris effect with multiple cloud layers may well be investigated with a simple 3.5-box model of the sort employed in LCH01. As the iris effect is the immediate response of clouds to SST, this shortwave component should be treated very cautiously. As noted above, the uncertainties in the shortwave feedback involve contributions other than those associated with the iris effect per se.

Acknowledgements This research was supported by Basic Science Research Program through the National Research Foundation of Korea (NRF) funded by the Ministry of Education (2018R1A6A1A08025520). The authors appreciate Dr. Jiwon Hwang for providing the figure.

Open Access This article is licensed under a Creative Commons Attribution 4.0 International License, which permits use, sharing, adaptation, distribution and reproduction in any medium or format, as long as you give appropriate credit to the original author(s) and the source, provide a link to the Creative Commons licence, and indicate if changes were made. The images or other third party material in this article are included in the article's Creative Commons licence, unless indicated otherwise in a credit line to the material. If material is not included in the article's Creative Commons licence and your intended use is not permitted by statutory regulation or exceeds the permitted use, you will need to obtain permission directly from the copyright holder. To view a copy of this licence, visit http://creativecommons.org/licenses/by/4.0/.

\section{References}

Bates, J.R.: Estimating climate sensitivity using two-zone energy balance models. Earth Space Sci. 3(5), 207-225 (2016). https://doi.org/10. 1002/2015EA000154

Bony, S., Stevens, B., Coppin, D., Becker, T., Reed, K.A., Voigt, A., Medeiros, B.: Thermodynamic control of anvil cloud amount. Proc. Natl. Acad. Sci. 113(32), 8927-8932 (2016)

Chambers, L.H., Lin, B., Young, D.F.: Examination of new CERES data for evidence of tropical iris feedback. J. Clim. 15(24), 3719-3726 (2002)

Cho, H., Ho, C.-H., Choi, Y.-S.: The observed variation in cloud-induced longwave radiation in response to sea surface temperature over the Pacific warm pool from MTSAT-1R imagery. Geophys. Res. Lett. 39, L18802 (2012). https://doi.org/10.1029/2012GL052700

Choi, Y.-S., Cho, H., Ho, C.-H., Lindzen, R.S., Park, S.K., Yu, X.: Influence of non-feedback variations of radiation on the determination of climate feedback. Theor. Appl. Climatol. 115(1-2), 355-364 (2014)

Choi, Y.-S., Ho, C.-H.: Radiative effect of cirrus with different optical properties over the tropics in MODIS and CERES observations. Geophys. Res. Lett. 33, 21 (2006). https://doi.org/10.1029/ 2006gl027403

Choi, Y.-S., Ho, C.-H., Sui, C.-H.: Different optical properties of high cloud in GMS and MODIS observations. Geophys. Res. Lett. 32, L23823 (2005)

Choi, Y.-S., Kim, W., Yeh, S.-W., Masunaga, H., Kwon, M.-J., Jo, H.-S., Huang, L.: Revisiting the iris effect of tropical cirrus clouds with 
TRMM and A-train satellite data. J. Geophys. Res. 122(11), 59175931 (2017)

Chou, M.-D., Lindzen, R.S.: Comments on "examination of the decadal tropical mean ERBS nonscanner radiation data for the iris hypothesis". J. Clim. 18, 2123-2127 (2005)

Chou, M.-D., Lindzen, R.S., Hou, A.Y.: Reply to: "tropical cirrus and water vapor: an effective earth infrared iris feedback?". Atmos. Chem. Phys. 2(1), 99-101 (2002a)

Chou, M.-D., Lindzen, R.S., Hou, A.Y.: Comments on "the iris hypothesis: a negative or positive cloud feedback?’. J. Clim. 15(18), 27132715 (2002b)

Chung, E.-S., Soden, B.J., Sohn, B.-J.: Revisiting the determination of climate sensitivity from relationships between surface temperature and radiative fluxes. Geophys. Res. Lett. 37, L10703 (2010)

Del Genio, A.D., Kovari, W.: Climatic properties of tropical precipitating convection under varying environmental conditions. J. Clim. 15(18), 2597-2615 (2002)

Forster, P.M., Gregory, J.M.: The climate sensitivity and its components diagnosed from earth radiation budget data. J. Clim. 19, 39-52 (2006)

Fu, Q., Baker, M., Hartmann, D.L.: Tropical cirrus and water vapor: an effective earth infrared iris feedback? Atmos. Chem. Phys. 2(1), 3137 (2002)

Fyfe, J.C., Gillett, N.P., Zwiers, F.W.: Overestimated global warming over the past 20 years. Nat. Clim. Chang. 3(9), 767-769 (2013)

Hartmann, D.L., Michelsen, M.L.: No evidence for iris. Bull. Am. Meteorol. Soc. 83(2), 249-254 (2002a)

Hartmann, D.L., Michelsen, M.L.: Reply to Lindzen, Chou, and Hou comment on "no evidence for iris". Bull. Am. Meteorol. Soc. 83, $1349-1352$ (2002b)

Horváth, Á., Soden, B.J.: Lagrangian diagnostics of tropical deep convection and its effect upon upper-tropospheric humidity. J. Clim. 21(5), 1013-1028 (2008). https://doi.org/10.1175/2007jcli1786.1

Houze Jr., R.A.: Cloud Dynamics. Academic, San Diego (2014)

Hwang, J., Choi, Y.S., Su, H., Jiang, J.H.: Invariability of Arctic top-ofatmosphere radiative response to surface temperature changes. Earth Space Sci. 7(11), e2020EA001316 (2020)

Hwang, J., Choi, Y.-S., Yoo, C., Wang, Y., Su, H., Jiang, J.H.: Interpretation of top of the atmosphere energy flux for future Arctic warming. Sci. Rep. 9, 13059 (2019)

Igel, M.R., Drager, A.J., van den Heever, S.C.: A CloudSat cloud object partitioning technique and assessment and integration of deep convective anvil sensitivities to sea surface temperature. J. Geophys. Res. Atmos. 119(17), 10515-10535 (2014)

Igel, M.R., van den Heever, S.C.: The relative influence of environmental characteristics on tropical deep convective morphology as observed by CloudSat. J. Geophys. Res. Atmos. 120(9), 4304 4322 (2015)

Jansen, M., Ferrari, R.: Equilibration of an atmosphere by adiabatic eddy fluxes. J. Atmos. Sci. 70(9), 2948-2962 (2013)

Kang, H., Choi, Y.S., Hwang, J., Kim, H.S.: On the cloud radiative effect for tropical high clouds overlying low clouds. Geosci. Lett. 7(1), 1-6 (2020)

Kiehl, J.T.: On the observed near cancellation between longwave and shortwave cloud forcing in tropical regions. J. Clim. 7, 559-565 (1994)

Kubar, T.L., Jiang, J.H.: Net cloud thinning, low-level cloud diminishment, and Hadley circulation weakening of precipitating clouds with tropical West Pacific SST using MISR and other satellite and reanalysis data. Remote Sens. 11(10), 1250 (2019)

Lewis, N., Curry, J.A.: The implications for climate sensitivity of AR5 forcing and heat uptake estimates. Clim. Dyn. 45(3), 1009-1023 (2015)

Li, R.L., Storelvmo, T., Fedorov, A.V., Choi, Y.-S.: A positive iris feedback: insights from climate simulations with temperature sensitive cloud-rain conversion. J. Clim. 32(16), 5305-5324 (2019)
Lin, B., Wielicki, B.A., Chambers, L.H., Hu, Y., Xu, K.-M.: The iris hypothesis: a negative or positive cloud feedback? J. Clim. 15(1), 3-7 (2002). https://doi.org/10.1175/1520-0442(2002)015<0003: TIHANO $>2.0 . \mathrm{CO} ; 2$

Lin, B., Wielicki, B.A., Minnis, P., Chambers, L.H., Xu, K.-M., Hu, Y., Fan, A.: The effect of environmental conditions on tropical deep convective systems observed from the TRMM satellite. J. Clim. 19(22), 5745-5761 (2006)

Lin, B., Wong, T., Wielicki, B.A., Hu, Y.: Examination of the decadal tropical mean ERBS nonscanner radiation data for the iris hypothesis. J. Clim. 17(6), 1239-1246 (2004)

Lindzen, R.S.: Response to "greenhouse warming and the tropical water budget". Bull. Am. Meteor. Soc. 71, 1465-1467 (1990)

Lindzen, R.S.: Climate physics, feedbacks, and reductionism (and when does reductionism go too far?). Eur. Phys. J. Plus. 127, 52 (2012). https://doi.org/10.1140/epjp/i2012-12052-8

Lindzen, R.S.: On climate sensitivity. $\mathrm{CO} 2$ Coalition. https:// co2coalition.org/wp-content/uploads/2020/04/Climate-Sensitivity06.07.20.pdf. (2019) Accessed 26 Mar 2021

Lindzen, R.S.: An oversimplified picture of the climate behavior based on a single process can lead to distorted conclusions. Eur. Phys. J. Plus. 135, 462 (2020)

Lindzen, R.S., Choi, Y.-S.: On the determination of climate feedbacks from ERBE data. Geophys. Res. Lett. 36(16), (2009). https://doi. org/10.1029/2009GL039628

Lindzen, R.S., Choi, Y.-S.: On the observational determination of climate sensitivity and its implications. Asia- Pac. J. Atmos. Sci. 47(4), 377390 (2011). https://doi.org/10.1007/s13143-011-0023-x

Lindzen, R.S., Chou, M.-D., Hou, A.Y.: Does the earth have an adaptive infrared iris? Bull. Am. Meteor. Soc. 82(3), 417-432 (2001)

Lindzen, R.S., Chou, M.-D., Hou, A.Y.: Comment on "no evidence for iris". Bull. Am. Meteor. Soc. 83(9), 1345-1349 (2002)

Lindzen, R.S., Christy, J.R.: The global mean temperature anomaly record: how it works and why it is misleading. $\mathrm{CO} 2$ Coalition. http:// co2 coalition.org/wp-content/uploads/2020/12/Global-MeanTemperature-Anomaly-Record 12.08.20.pdf. (2020) Accessed 26 Mar 2021

Lindzen, R.S., Hou, A.Y., Farrell, B.: The role of convective model choice in calculating the climate impact of doubling $\mathrm{CO}_{2}$. J. Atmos. Sci. 39, 1189-1205 (1982)

Liou, K.-N.: Influence of cirrus clouds on weather and climate processes: a global perspective. Mon. Weather Rev. 114(6), 1167-1199 (1986)

Luo, Z., Rossow, W.B.: Characterizing tropical cirrus life cycle, evolution, and interaction with upper-tropospheric water vapor using Lagrangian trajectory analysis of satellite observations. J. Clim. 17, 4541-4563 (2004)

Mace, G.G., Zhang, Q., Vaughan, M., Marchand, R., Stephens, G., Trepte, C., Winker, D.: A description of hydrometeor layer occurrence statistics derived from the first year of merged Cloudsat and CALIPSO data. J. Geophys. Res. Atmos. 114, D8 (2009)

Manabe, S., Wetherald, R.T.: The effects of doubling the $\mathrm{CO}_{2}$ concentration on the climate of a general circulation model. J. Atmos. Sci. 32(1), 3-15 (1975)

Mauritsen, T., Stevens, B.: Missing iris effect as a possible cause of muted hydrological change and high climate sensitivity in models. Nat. Geosci. 8(5), 346-351 (2015). https://doi.org/10.1038/ngeo2414

Muller, C., Bony, S.: What favors convective aggregation and why? Geophys. Res. Lett. 42(13), 5626-5634 (2015)

Murphy, D.M.: Constraining climate sensitivity with linear fits to outgoing radiation. Geophys. Res. Lett. 37, L09704 (2010)

Nilsson, J., Emanuel, K.: Equilibrium atmospheres of a two-column radiative-convective model. Q. J. R. Meteorol. Soc. 125(558), 2239 2264 (1999)

Ohno, T., Satoh, M.: Roles of cloud microphysics on cloud responses to sea surface temperatures in radiative-convective equilibrium 
experiments using a high-resolution global nonhydrostatic model. J. Adv. Model. Earth Syst. 10(8), 1970-1989 (2018)

Ohno, T., Satoh, M., Noda, A.: Fine vertical resolution radiativeconvective equilibrium experiments: roles of turbulent mixing on the high-cloud response to sea surface temperatures. J. Adv. Model. Earth Syst. 11(6), 1637-1654 (2019)

Rapp, A.D., Kummerow, C., Berg, W., Griffith, B.: An evaluation of the proposed mechanism of the adaptive infrared iris hypothesis using TRMM VIRS and PR measurements. J. Clim. 18(20), 4185-4194 (2005)

Retsch, M.H., Mauritsen, T., Hohenegger, C.: Climate change feedbacks in aquaplanet experiments with explicit and parametrized convection for horizontal resolutions of 2,525 up to $5 \mathrm{~km}$. J. Adv. Model. Earth Syst. 11(7), 2070-2088 (2019)

Reverdy, M., Noel, V., Chepfer, H., Legras, B.: On the origin of subvisible cirrus clouds in the tropical upper troposphere. Atmos. Chem. Phys. 12(24), 12081-12101 (2012)

Rondanelli, R., Lindzen, R.S.: Observed variations in convective precipitation fraction and stratiform area with sea surface temperature. J. Geophys. Res. 113, D16 (2008). https://doi.org/10.1029/ 2008JD010064

Rondanelli, R., Lindzen, R.S.: Comment on "variations of tropical upper tropospheric clouds with sea surface temperature and implications for radiative effects" by H. Su et al. J. Geophys. Res. Atmos. 115, D6 (2010a)

Rondanelli, R., Lindzen, R.S.: Can thin cirrus clouds in the tropics provide a solution to the faint young Sun paradox? J. Geophys. Res. 115, D2 (2010b). https://doi.org/10.1029/2009JD012050

Sagan, C., Mullen, G.: Earth and Mars: evolution of atmospheres and surface temperatures. Science. 177(4043), 52-56 (1972)

Saint-Lu, M., Bony, S., Dufresne, J.L.: Observational evidence for a stability iris effect in the tropics. Geophys. Res. Lett. 47(14), e2020GL089059 (2020). https://doi.org/10.1029/2020GL089059

Seeley, J.T., Jeevanjee, N., Langhans, W., Romps, D.M.: Formation of tropical anvil clouds by slow evaporation. Geophys. Res. Lett. 46(1), 492-501 (2019). https://doi.org/10.1029/2018GL080747

Sherwood, S.C., Webb, M.J., Annan, J.D., Armour, K.C., Forster, P.M., Hargreaves, J.C., Watanabe, M.: An assessment of Earth's climate sensitivity using multiple lines of evidence. Rev. Geophys. 58(4), e2019RG000678 (2020)

Spencer, R.W., Braswell, W.D.: How dry is the tropical free troposphere? Implications for global warming theory. Bull. Am. Meteor. Soc. 78(6), 1097-1106 (1997)

Stott, P., Good, P., Jones, G., Gillett, N., Hawkins, E.: The upper end of climate model temperature projections is inconsistent with past warming. Environ. Res. Lett. 8(1), 014024 (2013)
Su, H., Jiang, J.H., Gu, Y., Neelin, J.D., Kahn, B.H., Feldman, D., Yung, Y.L., Waters, J.W., Livesey, N.J., Santee, M.L., Read, W.G.: Variations of tropical upper tropospheric clouds with sea surface temperature and implications for radiative effects. J. Geophys. Res. 113, D10 (2008). https://doi.org/10.1029/2007JD009624

Su, H., Jiang, J.H., Neelin, J.D., Shen, T.P., Zhai, C., Yue, Q., Wang, Z., Huang, L., Choi, Y.-S., Stephens, G.L., Yung, Y.L.: Tightening of tropical ascent and high clouds key to precipitation change in a warmer climate. Nat. Commun. 8, 15771 (2017)

Sui, C.H., Satoh, M., Suzuki, K.: Precipitation efficiency and its role in cloud-Radiative feedbacks to climate variability. J. Meteorol. Soc. Japan. 98(2), 261-282 (2020)

Sun, D.-Z., Lindzen, R.S.: Distribution of tropical tropospheric water vapor. J. Atmos. Sci. 50(12), 1643-1660 (1993)

Tobin, I., Bony, S., Roca, R.: Observational evidence for relationships between the degree of aggregation of deep convection, water vapor, surface fluxes, and radiation. J. Clim. 25(20), 6885-6904 (2012)

Trenberth, K.E., Fasullo, J.T.: Global warming due to increasing absorbed solar radiation. Geophys. Res. Lett. 36(7), (2009). https:// doi.org/10.1029/2009GL037527

Trenberth, K.E., Fasullo, J.T., O'Dell, C., Wong, T.: Relationships between tropical sea surface temperature and top-of-atmosphere radiation. Geophys. Res. Lett. 37, L03702 (2010)

Trenberth, K.E., et al.: Issues in establishing climate sensitivity in recent studies. Remote Sens. 3, 2051-2056 (2011). https://doi.org/10. 3390/rs3092051

Udelhofen, P.M., Hartmann, D.L.: Influence of tropical cloud systems on the relative humidity in the upper troposphere. J. Geophys. Res. Atmos. 100(D4), 7423-7440 (1995)

Williams, I.N., Pierrehumbert, R.T.: Observational evidence against strongly stabilizing tropical cloud feedbacks. Geophys. Res. Lett. 44, 1503-1510 (2017)

Wing, A.A., Emanuel, K.A.: Physical mechanisms controlling selfaggregation of convection in idealized numerical modeling simulations. J. Adv. Model. Earth Syst. 6(1), 59-74 (2014)

Zelinka, M.D., Hartmann, D.L.: The observed sensitivity of high clouds to mean surface temperature anomalies in the tropics. J. Geophys. Res. Atmos. 116, D23 (2011)

Zhao, M., Golaz, J.C., Held, I.M., Ramaswamy, V., Lin, S.J., Ming, Y. Ginoux, P., Wyman, B., Donner, L.J., Guo, H.: Uncertainty in model climate sensitivity traced to representations of cumulus precipitation microphysics. J. Clim. 29(2), 543-560 (2016)

Publisher's Note Springer Nature remains neutral with regard to jurisdictional claims in published maps and institutional affiliations. 